\title{
AMPLIFICADORES DE POTENCIA DE RF/MICROONDAS ALTAMENTE EFICIENTES: EJEMPLOS DE DISEÑO
}

\section{HIGH EFFICIENCY RF/MICROWAVE POWER AMPLIFIERS: DESIGN EXAMPLES}

\author{
Ing. Norma Restrepo Burgos, Ing. Lady Fernanda Pérez Mancera, Esther Vanessa \\ Andrade Mesa, Carlos Alberto Ballesteros Tovar, MSc. Edison F. Angarita Malaver, \\ PhD. Jorge Julián Moreno Rubio Calle 4 Sur No. 15-134. Sogamoso, Boyacá, Colombia. Tel.: (+57-8) 7701643, Fax: (+57-8) 7430953, Ext. 212.
E-mail: \{norma.restrepo, ladyfernanda.perez, esther.andrade, carlos.ballesterostovar, \\ Universidad Pedagógica y Tecnológica de Colombia - Grupo de Investigación GINTEL. \\ edison.angarita, jorgejulian.moreno\} @uptc.edu.co
}

\begin{abstract}
Resumen: Este artículo muestra el diseño y la caracterización de dos amplificadores de potencia de alta eficiencia basados en tecnología GaN HEMT con una frecuencia de trabajo de $2.4 \mathrm{GHz}$. El primero es un amplificador de carga sintonizada con una eficiencia en saturación máxima de $52 \%$ y ganancia a pequeña señal de $14.2 \mathrm{~dB}$, el otro es un Clase $\mathrm{F}$ con un pico de eficiencia incrementado hasta el $60 \%$ y ganancia a pequeña señal de $16.4 \mathrm{~dB}$. Durante el proceso de diseño, se han tenido en cuenta las componentes parásitas debidas al empaquetado. Un dispositivo CGH40010 fabricado por Cree Inc. ha sido usado con un modelo no lineal válido hasta $6 \mathrm{GHz}$ y una potencia de salida esperada de $10 \mathrm{~W}$.
\end{abstract}

Palabras clave: Clase F, alta eficiencia, circuitos de microondas, carga sintonizada, amplificador de potencia.

\begin{abstract}
This paper shows the design and characterization of two high efficiency power amplifiers based on GaN-HEMT technology with operating frequency of $2.4 \mathrm{GHz}$. The first one is a Tuned Load with maximum saturated drain efficiency of $52 \%$, and small signal gain about $14.2 \mathrm{~dB}$. The other one is a Class $\mathrm{F}$ with $60 \%$ of maximum saturated efficiency, and small signal gain about $16.4 \mathrm{~dB}$. The parasitics of the device's package are taken into account on the design process. A Cree's CGH40010 device has been used with a nonlinear model guarantied up to $6 \mathrm{GHz}$ and with an expected output power of $10 \mathrm{~W}$.
\end{abstract}

Keywords: Class F, high efficiency, microwave circuits, tuned load, power amplifier.

\section{INTRODUCTION}

The power amplifier (PA) is one of the three main categories of amplifiers used in wireless systems. It is located at the output stage of the transmitter and increases the radiated power level (Pozar, 2000). In this way, the PA is hardly related to the system power consumption, and therefore, to the transmission cost.
On the other hand, efficiency is a major PA figure of merit. It is a measure of the DC- to RF-power transformation PA capability. Thus, high efficiency means that the PA minimizes DC power wasting, leading to lower transmission cost and more compact structures (Gao et al., 2006, Moreno et al., 2012). 
In this framework, different methodologies have been developed in order to design high efficiency PAs, including those of them using harmonic tuning techniques. As examples, we have, the wellknown, Tuned Load (TL) and Class-F structures.

This paper shows the design and characterization of two high-efficiency power amplifiers. The former is a TL PA with saturated efficiency of $52 \%$, and the latter is a Class-F with $60 \%$ of saturated efficiency. Both of them, with $2.4 \mathrm{GHz}$ as operating frequency, and they have been implemented using the $10 \mathrm{~W}$ GaN-HEMT CGH40010 device from Cree Inc. The obtained results demonstrate the Class-F PA superiority in terms of efficiency and gain in comparison with the TL one.

\section{OUTPUT TOPOLOGY}

\subsection{TL and Class-F Fundamental Loads.}

The TL PA offers more efficiency in comparison of quasi-linear conventional approaches like class A and class B. It is usually used as reference to compare and evaluate more efficient schemes. The TL technique exploits short-circuit terminations at the harmonic frequencies at the intrinsic drain active device, maximizing fundamental-frequency voltage and current swings. With a maximum swing achieved, the resulting output current waveform is a truncated sinusoidal and with the short-circuit terminations at all harmonic frequencies, the output drain voltage waveform is purely sinusoidal (Colantonio et al., 2009, Colantonio, et al., 2004). Thus, the TL PA optimum load at fundamental frequency $R_{T L}$ as function of the current conduction angle $\theta$, at the intrinsic drain reference plane, is given by (Rubio et al., 2013):

$$
R_{T L}(\theta)=\frac{V_{D D}-V_{k}}{I_{1}}
$$

Where $\mathrm{V}_{\mathrm{DD}}$ is the drain bias voltage, $\mathrm{V}_{\mathrm{k}}$ is the device knee voltage and $I_{1}(\theta)$ is the fundamental drain current.

The Class F design strategy has become a representative of the high efficiency amplifier, offering high output power and design simplicity. It is based on the idea of tuning to open circuit the load impedance at odd harmonics and tuning to short circuit the load impedance at even harmonics. Ideally, the drain voltage shapes a square wave, and the drain current, a half sinusoid wave, resulting in no-internal harmonic dissipation power, thus achieving $100 \%$ theoretical drain efficiency (Moon et al., 2012, Moreno Rubio et al., 2013, Ooi et al., 2004, Cripps 1999). The intrinsic drain optimum load at fundamental frequency is purely resistive and can be expressed in terms of the TL optimum load as (Colantonio et al., 2009):

$$
R_{F}=1.15 R_{T L}
$$

\subsection{Output Matching Network}

As shown in (Moreno-Rubio et al. 2014), in order to access the device intrinsic drain, the equivalent output reactive network (Lout and Cout) formed by the so-call device parasitics, has to be compensated by the output matching network (OMN) at the design frequencies. In this framework, an amplifier distributed OMN is proposed as shown in Fig. 1. Notice that several harmonic control sections could be included in order to generate, at the device intrinsic drain, short- or open-circuits depending on the harmonic tuned PA class. Finally, a compensation network is implemented in order to compensate the effects of Cout, Lout and harmonic control sections, at the fundamental frequency.

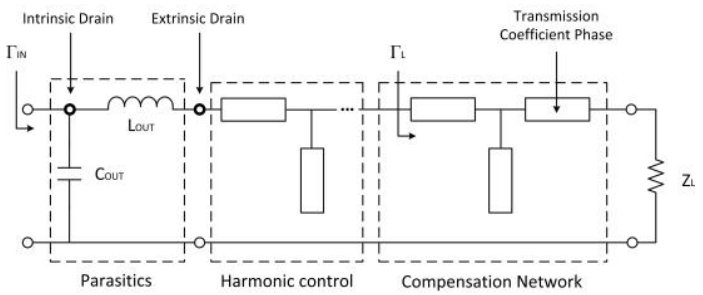

Fig. 1. Proposed distributed OMN scheme.

For the harmonic control sections, the transmission lines electrical lengths can be calculated as show in (Moreno-Rubio et al. 2014).

The device parasitics and harmonic control sections have associated a scattering matrix. According to (Moreno-Rubio et al. 2014), the value of $\Gamma_{L}$ (see Fig. 1) that compensates parasitics and harmonic control sections, is expressed as:

$$
\Gamma_{L}=\frac{S_{11}}{\Delta}
$$

Take into account that a series transmission line has to be included at the end of the network in order to adjust the transmission coefficient phase. 


\section{IMPLEMENTATION AND RESULTS}

The PAs have been designed taking into account the OMN topology shown in Fig. 1.The TL PA schematic is presented in Fig. 2, while Fig. 3 shows the class $\mathrm{F}$ one. For both, a $10-\mathrm{W}$ GaN HEMT CGH40010 device has been employed. The OMNs have been designed considering $\mathrm{R}_{\mathrm{TL}}=30 \Omega$ and $\mathrm{R}_{\mathrm{F}}$ $=34,5 \Omega$ according to (1) and (2) respectively.
On the other hand, the input matching networks (IMN) have been designed in order to match the device input impedance to the impedance source (usually $50 \Omega$ ), and to stabilize the circuit (Rubio, J. et al., 2013).

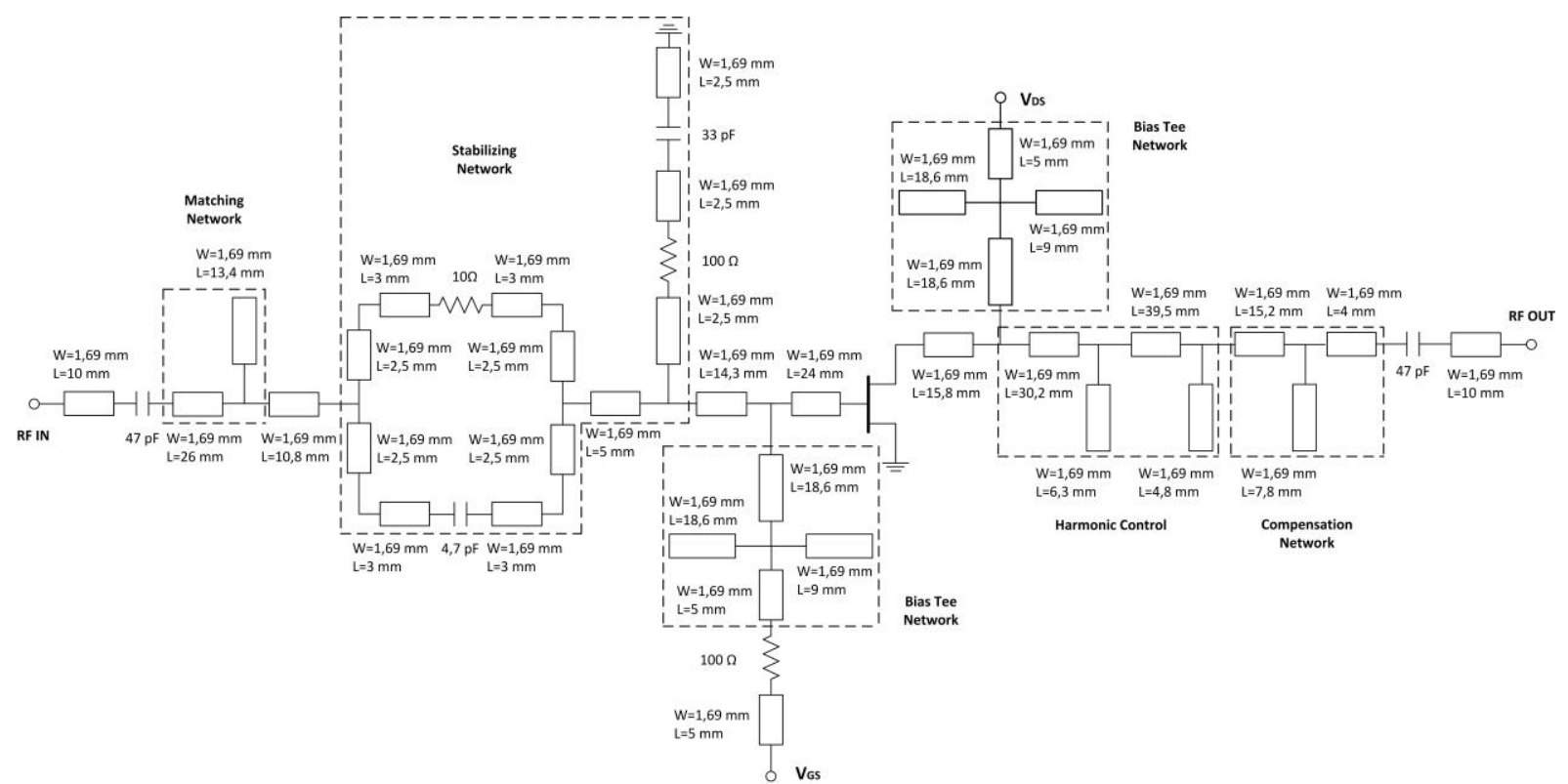

Fig. 2. TL PA schematic.

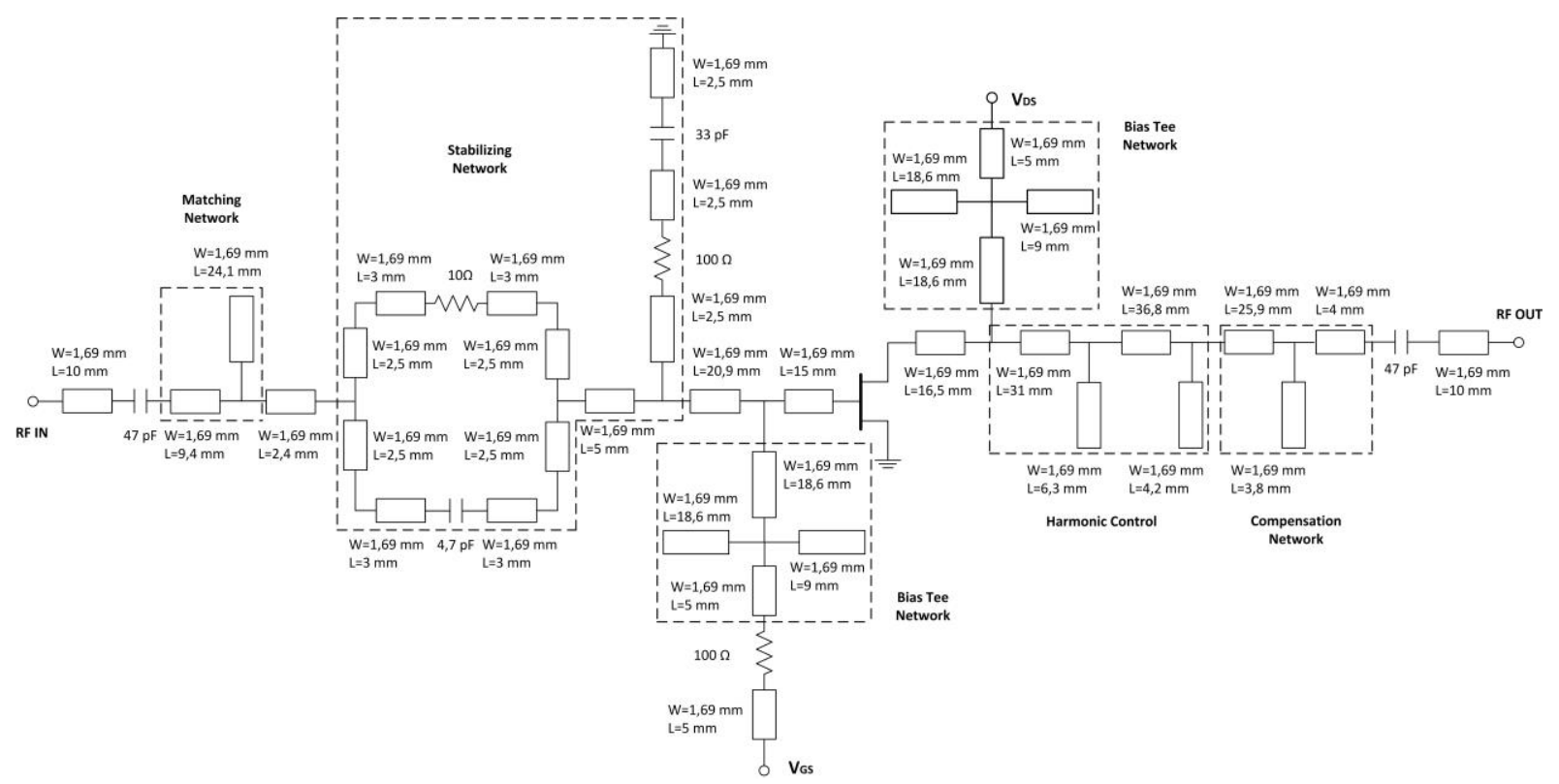

Fig. 3. Class F PA schematic 


\subsection{Characterization}

The time-domain drain current and voltage waveforms are simulated and depicted in Fig. 4 and Fig. 5. As can be notice, for both amplifiers, the drain currents tend to shape a truncated sinusoidal waveform, while the drain voltages tends to a pure sinusoidal waveform for the TL PA and a square one for the Class F PA, as expected. The implemented amplifiers are presented in Fig. 6 and Fig. 7, respectively.

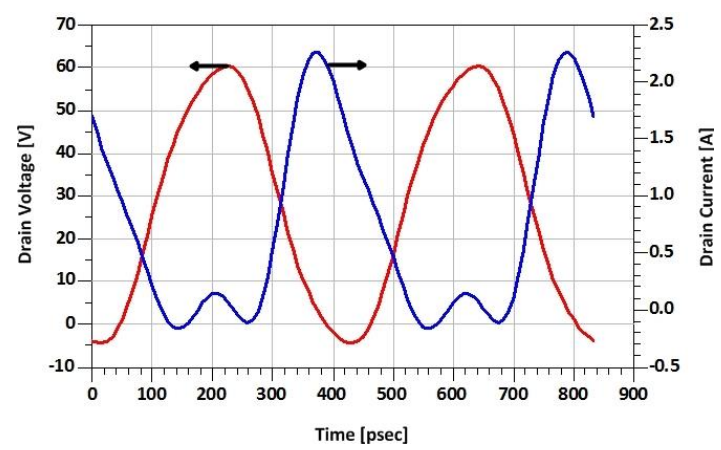

Fig. 4. TL PA intrinsic drain current (blue) and voltage (red) waveforms.

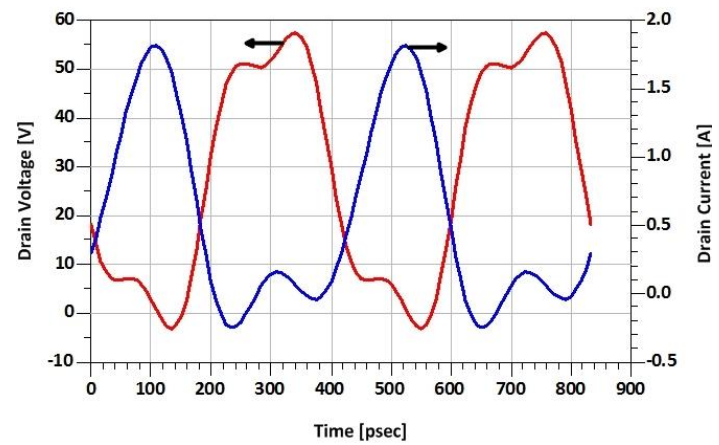

Fig. 5. Class F PA intrinsic drain current (blue) and voltage (red) waveforms.

After verifying the circuit stability for both PAs, a vector network analyzer (VNA) with operating frequency up to $8 \mathrm{GHz}$ is used to carry out the small signal measurements. Then, the large signal characterization is carried out through a set-up including the VNA, and a NRP-Z24 power sensor.

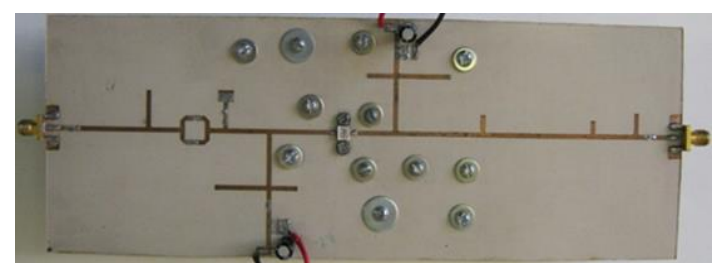

Fig. 6. Picture of de realized TL PA.

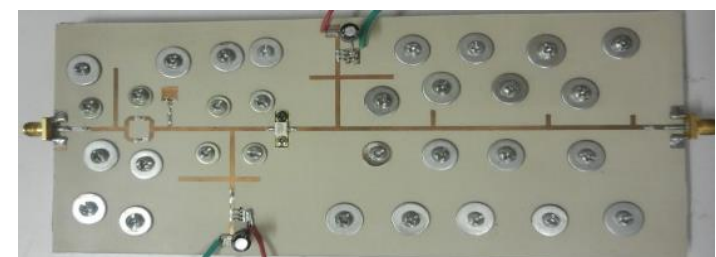

Fig. 7. Picture of de realized Class F PA.

Fig. 8 shows the PAs large signal characterization. The TL PA achieves a saturated efficiency of $52 \%$, and a small signal gain about $14.2 \mathrm{~dB}$. Otherwise, the Class $\mathrm{F}$ reaches a saturated efficiency of $60 \%$ and a small signal gain about $16.4 \mathrm{~dB}$, thus confirming, the predicted theoretical improvement. According to simulation, output power and gain are higher in Class $\mathrm{F}$ with respect to TL up to saturation, but the implemented Class $\mathrm{F}$ exhibits an early saturation that is being examined.

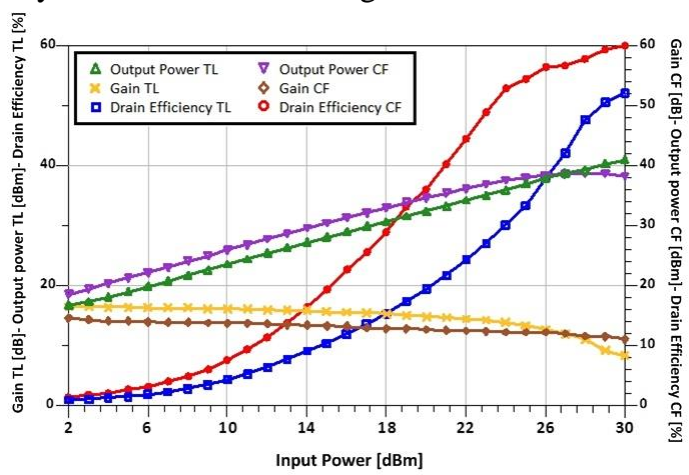

Fig. 8. Measured performance of TL and Class F amplifiers.

\section{CONCLUSIONS}

An experimental comparison between two high efficiency harmonics tuned microwave PAs was presented. It was carried out through the design, realization and characterization of a TL and a Class F PAs based on GaN HEMT technology operating at $2.4 \mathrm{GHz}$. An excellent simulated and measured performances were obtained. The obtained results show higher performance for Class $\mathrm{F}$ with respect to TL, thus confirming the predicted theoretical improvement. The obtained PAs are promising in terms of efficiency and will be considered in order to design more complex amplifying structures as Doherty Power Amplifiers.

\section{ACKNOWLEDGMENT}

The authors wish to acknowledge the support of Grupo de Investigación en Telecomunicaciones GINTEL, from the Universidad Pedagógica $y$ Tecnológica de Colombia. 


\section{REFERENCES}

Colantonio, P. et al., (2004). HF class F design guidelines. Microwaves, Radar and Wireless Communications, 2004. MIKON-2004. 15th International Conference on, IEEE.

Colantonio P. et al., (2009). High Efficiency RFand Microwave solid state power amplifiers. John Wiley \& Sons.

Cripps, S. C. (1999). RF power amplifiers for wireless communications, Artech House.

Gao, S., P. et al., (2006). Microwave class-F and inverse class-F power amplifiers designs using GaN technology and GaAs pHEMT. Microwave Conference, 2006. 36th European, IEEE.

Moon, J. et al., (2012). Behaviors of Class-F and Class-Amplifiers. Microwave Theory and Techniques, IEEE Transactions on 60(6): 1937-1951.

Moreno Rubio J., Jiménez López A, Barrera Lombana N. (2013). El amplificador de potencia de carga sintonizada. Revista colombiana de tecnologías de Avanzada. 2(22). Pág. $9-13$
Moreno, J. et al., (2012). Development of single stage and doherty GaN based hybrid RF power amplifiers for quasi constant envelope and high peak to average power ratio wireless standards. Microwave and optical technology letters, vol. 54, no 1, p. 206-210.

Moreno-Rubio, J., et al., (2014). Harmonic tuned $\mathrm{RF} /$ microwave high efficiency power amplifier design accessing the intrinsic drain. Central America and Panama Convention (CONCAPAN XXXIV), 2014 IEEE, IEEE. p. $1-6$.

Ooi, S. F. et al., (2004). High efficiency class-F power amplifier design. High Frequency Postgraduate Student Colloquium, 2004, IEEE. p. 113-118.

Pozar, D. M. (2000). Microwave and RF design of wireless systems, John Wiley \& Sons, Inc.

Rubio, J. et al., (2013). "El Amplificador De Potencia De Carga Sintonizada." Revista Colombiana de Tecnologías de Avanzada (RCTA). vol. 2, no 22. 